\title{
Analysis and Design of the Client in the Supervision System Based on Android
}

\author{
Shifeng Wu, Luo Zhong, Manli Hu, Huazhu Song \\ School of Computer Science and Technology, Wuhan University of Technology, Wuhan, P.R.China
}

\begin{abstract}
The Supervision for buildings plays the very important role in the period of construction and is closely linked with the life and property. In order to improve the management level of the supervision departments and offer better communication between the supervision departments and the construction side, the paper puts forward a solution which is applied to the mobile clients so that users can query and report on site and which can be conducted from following steps. According to the theory of the software engineering, the system's requirement analysis was given including the business requirements, the functional requirements and the user requirements, etc. Then, its outline design was shown with the overall architecture, the data design, and the user interface, and so was the system detailed design. Finally, the prototype system was achieved based on the android platform, and was tested. The test results show that this solution is feasible and valid.
\end{abstract}

Keywords-supervision system; android development; requirements analysis; system design; system implementation.

\section{INTRODUCTION}

At present, the information management of construction engineering system is continuously booming and construction engineering supervision system is an important part of information management of the construction engineering. Therefore, the study of house supervision system based on android can provide convenience for the development of the information engineering supervision, which supervises the bidding process, control the site of supervision, improve the quality of the supervision company and promote the health of the industry.

House Supervision System, combined with the development of information technology and generated based on the actual needs of the field, is responsible for the entire process of project bidding ${ }^{[1]}$. The details are as follows.

(1) In the bidding system, construction project and completed project modules, the whole process of which are controlled by information network. What's more, the process is carried out in strict accordance with the rules process, and is completely transparent to the public.

(2) In the construction project, it contains a series of review reconciliation for the receipt of the supervision costs.

(3) In the completed project, it is necessary to evaluate the construction company in all kinds of levels, the company director and supervisors, whose results will be input to the intelligent decision module. Thus, it is able to automatically assess the overall quality for each supervisor.
Currently, there are many studies on home and abroad supervision systems. And such systems are generally composed of five subsystems: Construction materials testing management system, internet network data exchange platform, the quality of the test data management platform integration, testing agency management information system and internet network publicity platform.

So, by using the housing supervision system, we can conduct the supervision work more comprehensive and strictly. When regulators oversee housing construction work at the site, they need a mobile client to connect to the supervision system. If the mobile system could be got, the management level can be improved.

\section{THE REQUIREMENT ANALYSIS OF THE SYSTEM}

Analysis of the client in the supervision system based on android includes 4 parts in this chapter. That is to say, this part analyzes the system from business requirements, functional requirements, user requirements and performance requirements. After the requirements, then, the 4 important functional modules can be determined.

\section{A. Business Requirements}

To strengthen the supervision of the housing construction and ensure the quality of housing construction is very important no matter for the government or individual. By using the housing supervision system, we can conduct the supervision work more comprehensive and strictly. When regulators oversee housing construction work at the site, they need a mobile client to connect to the supervision system. As a result, regulators can do the query and processing functions on the site conveniently, which can promote us to report the information we discussed and data on the site to the supervisors timely ${ }^{[2]}$.

\section{B. Functional Requirements}

Mobile client functional requirements:

(1) The login module. The users login the system by inputting the server-assigned account, which can be used to identify the account privileges.

(2) The picture uploaded module. The users can take photos while they find out housing construction quality problems, and upload them to the server.

(3) The query module. The users can query the quality problem reflected in the photos which are stored in the server.

(4) The Instant Messaging module. By using this function we can report some problems to the leaders or customers immediately. 


\section{User Requirements}

shown.

Analyze the system's user requirements, as Table 1

TABLE I. System Stimulus / Response SEquence Of USER RequirementS

\begin{tabular}{ll}
\hline \multicolumn{1}{c}{ stimulus } & \multicolumn{1}{c}{ response } \\
\hline $\begin{array}{l}\text { Login, input user account and password } \\
\text { Query, click the query button }\end{array}$ & $\begin{array}{l}\text { Verify the identity, if it is correctly then jump to the main menu interface, else, } \\
\text { returned } \\
\text { The client will display the data that received on the screen } \\
\text { Screen displays a detailed description of the problems, the construction unit and live } \\
\text { pictures } \\
\text { Jiew, click on a certain question }\end{array}$ \\
$\begin{array}{l}\text { Upload pictures, click the button to upload pictures } \\
\text { Take a photograph, click on the camera button }\end{array}$ & $\begin{array}{l}\text { Start System cameras } \\
\text { Upload, click the upload button }\end{array}$ \\
$\begin{array}{l}\text { Real-time commung to chat interface } \\
\text { Send , click the send button }\end{array}$ & $\begin{array}{l}\text { The chat will be sent to other side } \\
\text { Clear the screen, click on the button to clear the screen }\end{array}$ \\
Exit the system & $\begin{array}{l}\text { clear the chat } \\
\text { Log off, disconnect from the server }\end{array}$
\end{tabular}

\section{Performance requirements}

1) It requires fast response in UI, high speed in camera, data storage and processing, besides, the hardware of mobile phone should support it.

2) It requires us login the server and it needs fast upload speed, good user experience and refreshed interface once data updates.

3) It should standardized data format and ensure the security of upload and storage

\section{SYSTEM DESIGN}

The design of the system includes the outline design and the detailed design.

A summary of the design include 4 working, one is to design the system's overall process architecture and to build the program's logical framework, the other is to design the user interface, providing a beautiful and comfortable interactive environment ${ }^{[3]}$. The third one is to design the functional module. The last one is to design data storage and transmission formats.

\section{A. The overall system architecture design}

(1) Run mobile client and the program will connect to the server automatically. If the connection fails, you will need to enter the IP address of the server manually to reconnect, and then goto (3).

(2) Login screen, enter the account and password, if users login successfully, then goto (3).

(3) Main menu interface. If users click on the "Search" button, then goto (4); If users click on the "upload pictures" button, then goto (5); If users click on the "Instant Messaging" button, then go to (6).

(4) Query interface, quality problem list that is reported can be view, if users click a quality problem, then goto (7).

(5) Quality problem description Interface. The description of the problem and the relevant information can be uploaded together with photos to the server.
(6) Chat interface. Users can report the quality problems timely.

(7) Quality problems browsing interface. Check the specific details of the problem.

\section{B. User interaction overview diagram}

To analyze UI controls that maybe used in each interface of the system and design the layout of the various controls, trying to place them better, which makes users feel easy and comfort when users have interactions [4].

Summary of interface can be shown as figure 1 .

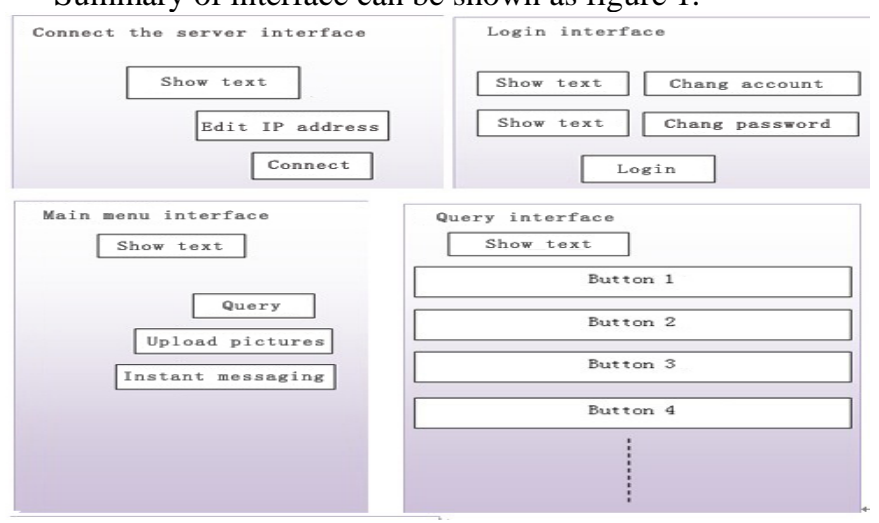

Figure 1. Summary of interface

\section{The Detailed design of the data}

According to E-R diagram, the user table, quality problem table, chats table established, which are shown as table 2, 3and 4. 
TABLE II. USER

\begin{tabular}{ccc}
\hline Field name & Data type & Primary key \\
\hline user_ID & varchar $(20)$ & yes \\
user_password & varchar $(20)$ & no \\
user_name & varchar $(20)$ & no
\end{tabular}

TABLE III. QUALity PROBLEM

\begin{tabular}{ccc}
\hline Field name & Data type & Primary key \\
\hline problem_ID & varchar $(20)$ & yes \\
user_ID & varchar $(20)$ & no \\
problem_name & varchar $(20)$ & no \\
problem_date & datetime & no \\
problem_descripe & varchar $(400)$ & no \\
unit_name & varchar $(100)$ & no \\
problem_image & image & no \\
\hline & TABLE IV.CHATs & \\
\hline Field name & Data type & Primary key \\
\hline chat_id & varchar $(20)$ & yes \\
chat_time & datetime & no \\
chat_text & varchar $(400)$ & no
\end{tabular}

\section{The Detailed design of function module}

(1) Login module design

Achieve the login function through the login interface

[5]. First, by using the method findViewById(id), it can get two text edit box objects, while through getText(), it can get account and password, then it's turn to bind the listener for login button, when click the login button, account and password will be sent to the server. If they are correctly, that means logging successfully, it needs to configure the properties, call start Activity(intent) to jump from the login interface to the main menu interface.

(2) Picture upload module design

Realize the camera and upload function in the upload interface. First, by using the method findViewById(id), it can get the camera button object and upload button object, and then bind the corresponding listeners(photo_listener and upload_listener) for the two buttons. When users click the camera button, it will call the method startActivityForResult() to start system cameras. Then, image data and pictures can be get by overwriting the method onActivityResult() in the Class Activity. When users click upload button, the pictures that has a description of problem will be sent to the server in a certain format.

As shown in Figure 2

(3) Query module design

To achieve the query function in query interface, the client will receive the data sent from server when users click the query button in the main menu, adding the appropriate number of buttons which will be bind with quality listened dynamically in Java code according to the number of quality problem received. When users click a certain quality problem, it jumps to Check_Activity to see pictures and detailed problem description.

As shown in Figure 3

(4) Instant Messaging module design

In the Instant messaging interface, chat function is achieved. First, by using the method findViewById(id), it can return 2 objects(send button object and clear screen button object), and then binding the corresponding listeners(Send_Listener and Send_Listener) for the two buttons ${ }^{[6]}$. While using the talk box, it is used for editing word, users can click the send button. If click the clear screen button, the current chats can be clear.

As shown in Figure 4.

\section{THE DETAILED UI DESIGN}

There are two methods setting the layout of the interface: one is configure various control properties by using $\mathrm{xml}$ tags in the layout files, such as the control's position coordinates, length and width, and the content text and so on, which is contribute to separate the logic design and interface design, the other is add controls in java codes, setting its various properties through the methods in the Class. It is obvious that if the controls can be configured in $\mathrm{xml}$, it is not necessary to use java code to add them, which is because the separate of logic design and interface design is beneficial for the development and maintenance of the program. But the layout file is not so strong, for static control, the previous method can be considered, for the controls that need to add and remove dynamically, it's better to take the second approach ${ }^{[7]}$.

\section{A. The implementation of the prototype system}

The Platform required for the program is Android 1.6 above $^{[8-10]}$. Go to the login interface, shown in figure 5 .

Enter the correct IP address, the connection to the server was successful. Go to the main menu interface, shown in figure 6.

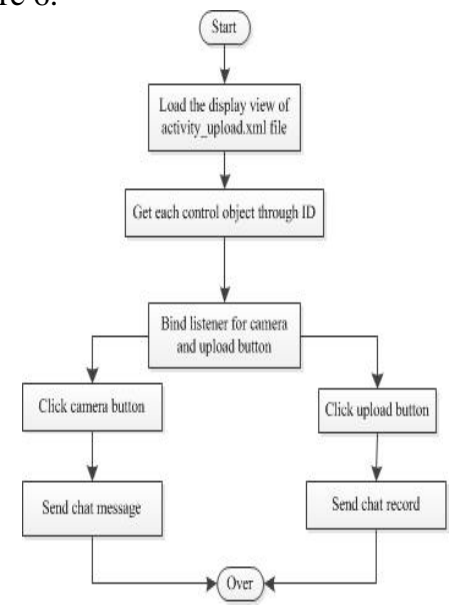

Figure 2 Picture upload module flow chart 


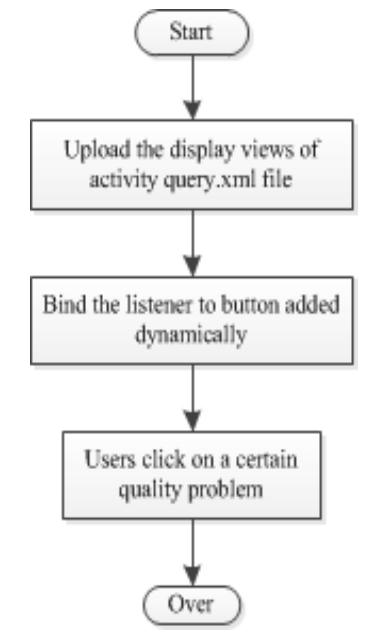

Figure 3. Query module flow chart

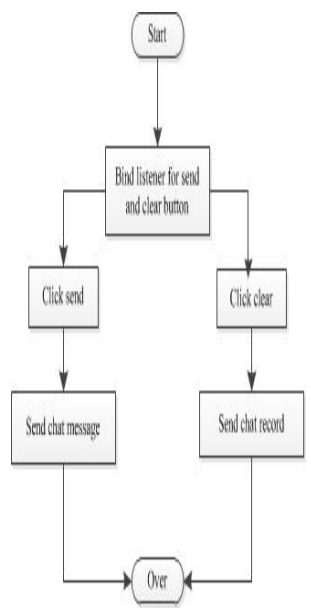

Figure 4. Instant messaging module flow chart

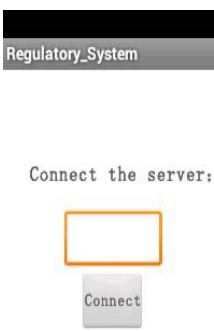

Figure 5. Start Interface

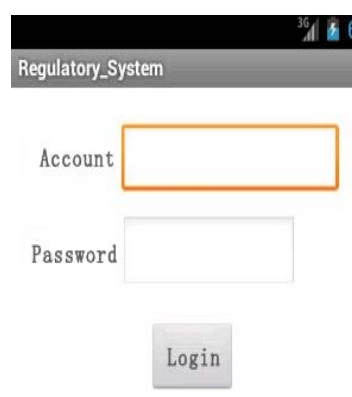

Figure 6. Login Interface

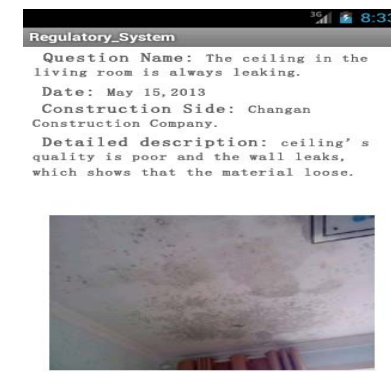

Figure 7. Main menu interface

Users enter the account and password, and then verified by the server, if it is correct, then, jump to the main menu interface, shown as figure 7.

When users click query button, the client will receive the data from server, then jump to query interface, shown as figure 8.

When users click a certain problem, the detail of the problem can be viewed. Jump to browse interface, shown as figure 9.

Return, when users click picture upload button, it will jump to upload interface, shown as figure 10.

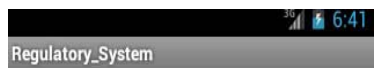

Welcome! Tang shiwei.

\section{Query}

Upload pictures

Instant messaging

Figure 8. Query interface

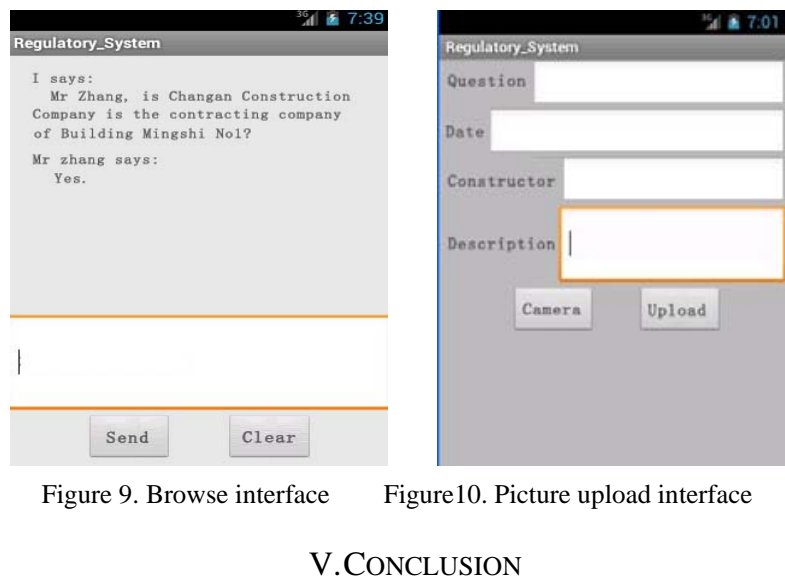

By using the housing supervision system, can the supervision work be conducted more comprehensive and strictly. When regulators oversee housing construction work at the site, they need a mobile client to connect to the 
supervision system. As a result, regulators can do the query and processing functions on the site conveniently, which can promote us to report the information we discussed to the supervisors timely, and it will improve the management level.

\section{REFERENCES}

[1] Gu, XiangBo \& Yu, Yun \& Chen, Qing. Construction project bidding theory and practice. China Petrochemical Press, 2007. (in Chinese)

[2] RickRogers. Android Application. Development People's Posts and Telecommunications Press, 2010. (in Chinese)

[3] Android Development Zone [EB/ON], http:// www.oschina.net/ android/ (in Chinese)

[4] Zhang Haifan. Introduction to Software Engineering (5th edition), Tsinghua University Press 2008. (in Chinese)
[5] Cay Horstmann. Object-Oriented Design \& Patterns. Electronic Industry Press, 2004. (in Chinese)

[6] Yang, cui\& He, Yaru. MySQL database applications from entry to the master. China Railway Press, 2013. (in Chinese)

[7] Bruce Eckel. Thinking in Java. Machinery Industry Press, 2007. (in Chinese)

[8] Song, Zengbin \& Huang, Jin \& Wu, Guangxu. Browse Conference Publications, Computer Science and Informat...

[9] Matrix-based android UI development[c], Proceeding of Computer Science and Information Processing, Xi'an, Shaanxi , 24-26 Aug. $2012: 185$ - 187

[10] Takala, T. \& Katara, M. \& Harty, J. Experiences of System-Level Model-Based GUI Testing of an Android Application [C], Proceeding of Software Testing, Verification and Validation, Berlin, 21-25 March 2011:377 - 386 